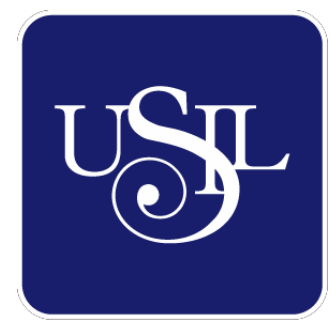

UNIVERSIDAD

SAN IGNACIO

DE LOYOLA

ESCUELA DE POSTGRADO

\title{
SERVICIO DE DESCARBONIZADO DE BANDEJAS PARA PANIFICADORAS DE SUPERMERCADOS EN LIMA Y CALLAO
}

Tesis para optar el grado de:

LELIA MARÍA ROSARIO DE OLAZÁVAL BEJARANO

Maestro en Ciencias Empresariales con Mención en Gestión Comercial

\section{JULIANA VILMA TORRES MARAVÍ}

Maestro en Ciencias Empresariales con Mención en Gestión Comercial

$$
\text { DAVID IVÁN QUIRÓS ZAVALA }
$$

Maestro en Ciencias Empresariales con Mención en Gestión de Finanzas

Asesor:

Luis Fernando Peredo Rojas

$$
\text { Lima - Perú }
$$

2018 
Agradecemos a la escuela de post grado de la Universidad San Ignacio de Loyola, que nos brindó todos los conocimientos que nos permitieron elaborar este plan de negocio.

A todos los profesores, amigos, conocidos y familiares que nos ayudaron a desarrollar y culminar nuestro deseo de ser maestro, y en forma especial a cada una de las personas que nos orientaron de forma desinteresada. 


\section{Resumen Ejecutivo}

El presente plan de negocio detallará la viabilidad y la implementación del servicio de descarbonización para las bandejas de panadería de supermercados de Lima y Callao, la planta se ubicará en el distrito de Lince entre los años 2018 a 2022 y la empresa se denominará Limpia Express S A.

El servicio que se ofrece es innovador, la oportunidad está en el rubro de servicios tercerizados de limpieza especializada en salas de producción de los supermercados, cabe resaltar, que actualmente, este servicio no lo realiza ninguna empresa a nivel nacional, por ende, no tiene competencia, el cual ofrecerá a los clientes una experiencia distinta, satisfaciendo sus necesidades de mantener las bandejas de producción de panadería limpias, sin residuos carbonizados y evitar observaciones ante las fiscalizaciones de las municipalidades.

Según la Asociación Peruana de Empresarios de la Panadería y Pastelería (ASPAN), en el Perú existen 10,000 panaderías pastelerías, Lima concentra el $43 \%$ y dentro de este porcentaje, las panaderías de los supermercados representan el 2\%; considerando que la tendencia de los últimos 6 años es seguir expandiéndose en Lima y en el Perú.

En el 2012, la Dirección General de Salud (DIGESA) colocó como requisito para todos los establecimientos de expendio de alimentos y bebidas, la "Habilitación Sanitaria y Validación Técnica Oficial del Plan HACCP”; mediante el Decreto Supremo N007-98-SA: Reglamento sobre Vigilancia y Control Sanitario de Alimentos y Bebidas. Las municipalidades son los entes encargados de la supervisión, si detectará el incumplimiento de los prerrequisitos durante sus fiscalizaciones, la sanción será una multa y/o cierre de local. 
Desde el 2015 a la fecha, las municipalidades observarón los residuos de masa quema o carbonizada adheridos a su superficie de las bandejas de producción de pan, según la Resolución Ministerial N 1020-2010 MINSA: Norma Sanitaria para la Fabricación, Elaboración y Expendio de Productos de Panificación, Galletería y Pastelería, en el ítem 6.5.4 indica que todo utensilio debe estar limpio y libre de cualquier contaminante o residuo que contamine al pan.

El presente plan de negocio plantea al cliente contar con un servicio semi automatizado para la descarbonización de las bandejas de producción de panadería, el cual se realizará fuera de su instalación, se adaptará a su operación, se retirará con eficiencia los residuos de masa quemados o carbonizados, con precios accesibles, de rápida atención y ofreciéndole ahorro de gastos operativos.

La inversión ha sido evaluada para un horizonte de 5 años, siendo la inversión inicial requerida de S/ 318,197.88 de los cuales se financiará a través de un préstamo 33en la entidad "Mi Banco" con un monto de S/ 127,279.15 a un plazo de pago de 5 años, con una TEA 48\% y el TCEA es de 49.24\%; obteniendo un tiempo de recuperación de la inversión en 3 años y 6 meses, así mismo, el aporte de capital de los socios es de S/ 190,918.73 que representa el 60\% de la inversión total.

Al determinar el flujo económico bajo las condiciones previamente expuestas, se obtiene como resultado un VANE positivo de S/ 969,229; VANF positivo de S/ 1, 064,167, con un TIRE del $58.68 \%$ y un TIRF del $64.52 \%$; por consiguiente, se concluye, que el presente plan de negocio es factible y viable, por ende, se recomienda su ejecución teniendo en consideración que el plan de negocio continuará con su operación indeterminadamente. 


\section{Tabla de Contenido}

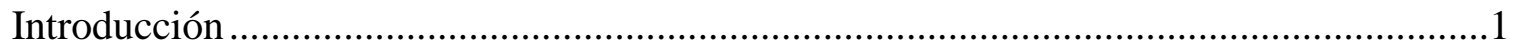

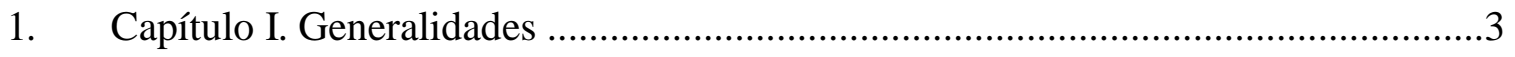

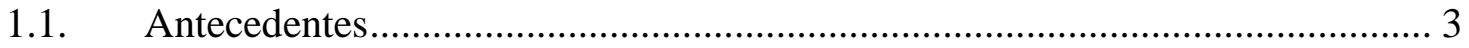

1.1.1. Evolución del sector panadero en el Perú. ....................................................... 3

1.1.2. Situación actual de supermercados en el Perú. ……………………………... 5

1.1.3. Buenas prácticas de manufactura (BPM) ……............................................ 7

1.1.4. Generación de sustancia tóxica Acrilamina. ……………………………....... 8

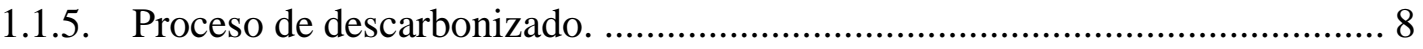

1.2. Determinación del Problema u Oportunidad ..................................................... 9

1.2.1. Oportunidad. 9

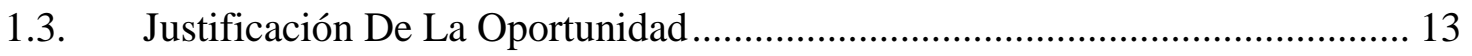

1.4. Determinación Factor Diferenciadora y Factores De Posicionamiento........... 14

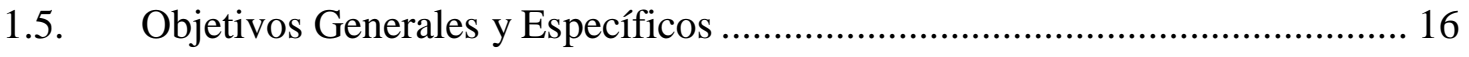

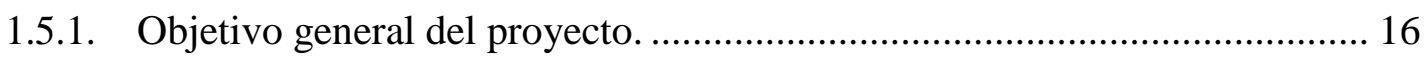

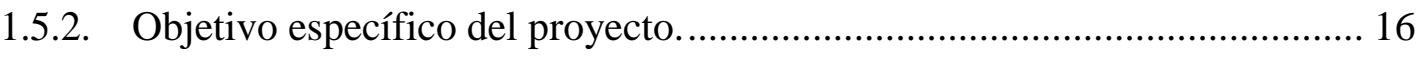

1.6. Alcances y Limitaciones en la Investigación ................................................... 16

1.6.1. Alcances. 16

1.6.2. Limitaciones. 17

2. Capítulo II. Descripción de la Empresa ..................................................................18

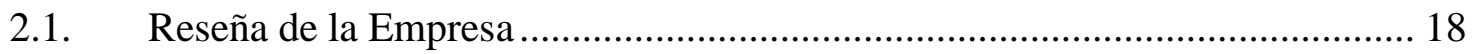


2.2. Estructura Organizacional .................................................................. 18

2.3. Producto y/o Servicio .............................................................................. 20

2.3.1. Ciclo de vida del servicio y de la empresa ................................................. 20

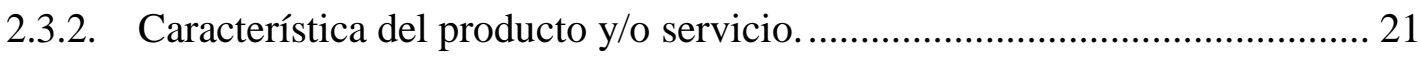

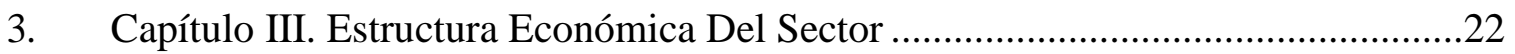

3.1. Análisis del Contexto Actual y Esperado ..................................................... 22

3.1.1. Análisis político gubernamental.............................................................. 23

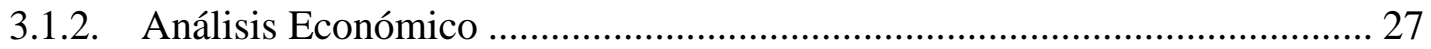

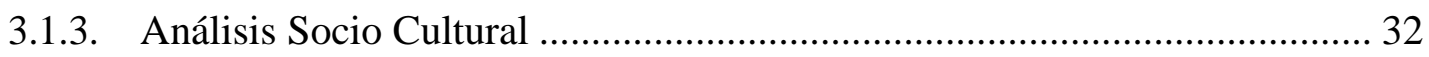

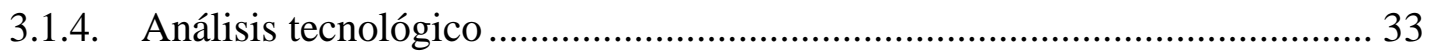

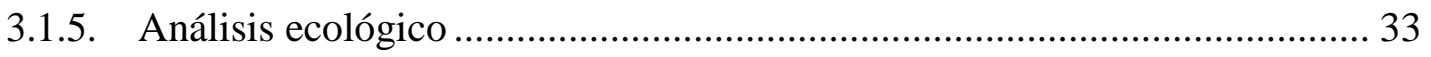

3.1.6. Análisis legal. 34

3.2. Descripción Del Estado Actual De La Industria ............................................. 35

3.2.1. Ciclo de vida de la industria....................................................................... 35

3.2.2. Segmentación de la industria. ..................................................................... 37

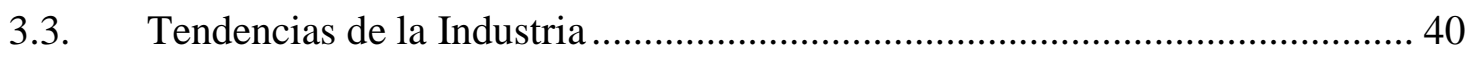

3.4. Análisis Competitivo del sector industrial...................................................... 43

3.4.1. Poder de negociación de los clientes............................................................ 43

3.4.2. Poder de negociación de los proveedores. .................................................... 47

3.4.1. Amenaza de servicios sustitutos................................................................ 49

3.4.2. Amenaza de nuevos competidores potenciales........................................... 51

3.4.3. Rivalidad entre competidores actuales...................................................... 53

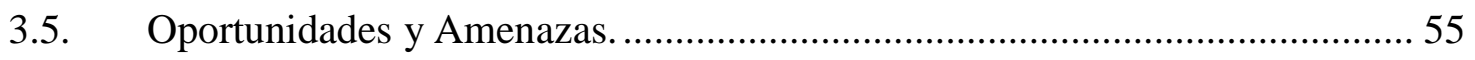

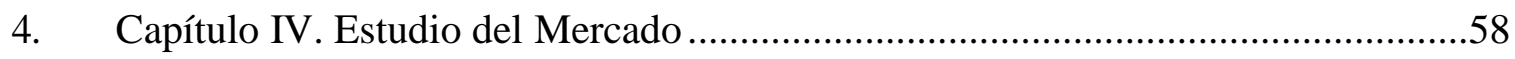


4.1. Selección del Segmento del Mercado.......................................................... 58

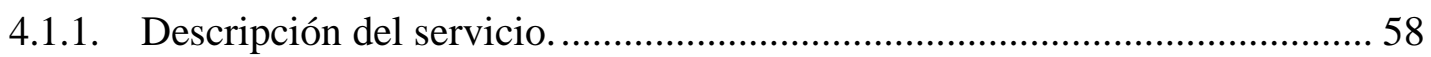

4.1.2. Segmentación de mercado.......................................................................... 59

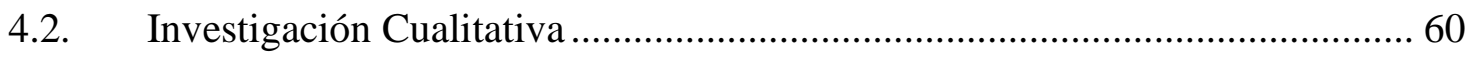

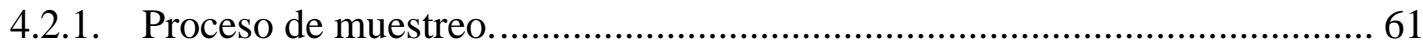

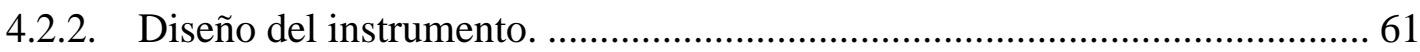

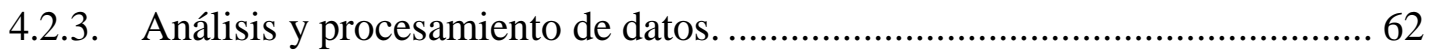

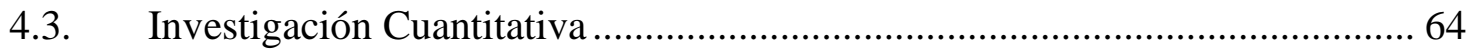

4.3.1. Proceso de muestreo de la investigación cuantitativa ................................... 64

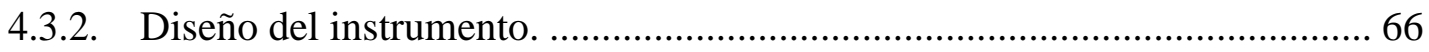

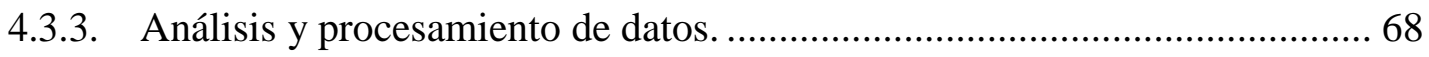

4.4. Conclusiones y Recomendaciones del Estudio Cualitativo y Cuantitativo ..... 80

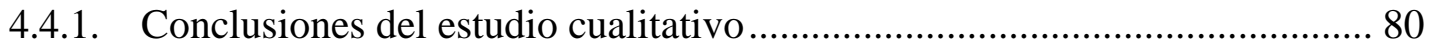

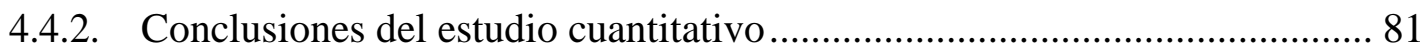

4.4.3. Recomendaciones del estudio cuantitativo y cualitativo.............................. 82

4.5. Perfil del consumidor tipo y sus variantes................................................... 82

5. Capítulo V. Proyección del Mercado Objetivo............................................................87

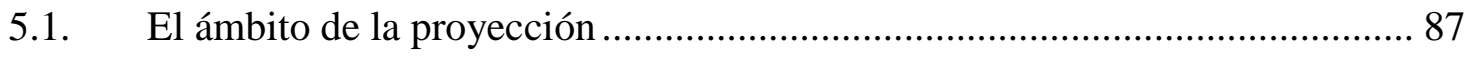

5.2. Selección del método de proyección .................................................................. 88

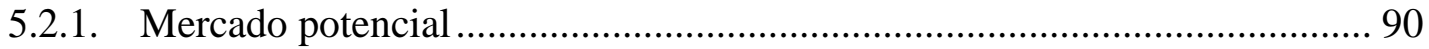

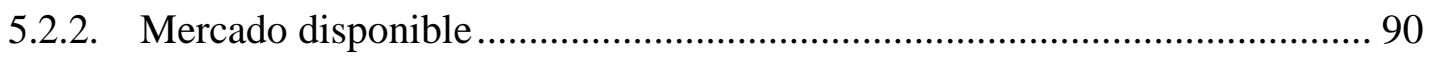

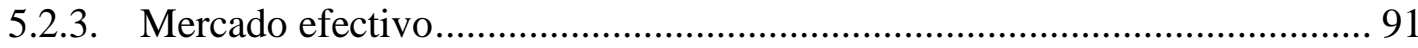

5.2.4. Mercado objetivo ……………………………........................................ 92

6. Capítulo VI. Plan de Marketing ............................................................................93 


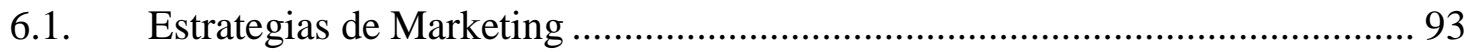

6.1.1. Estrategia de Producto / Servicio .................................................................. 93

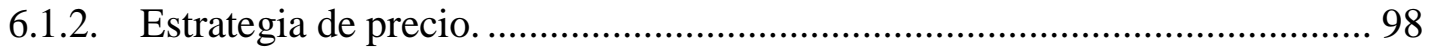

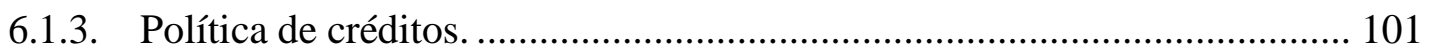

6.1.4. Estrategia de plaza y distribución................................................................... 101

6.1.5. Estrategia de promoción y marketing......................................................... 103

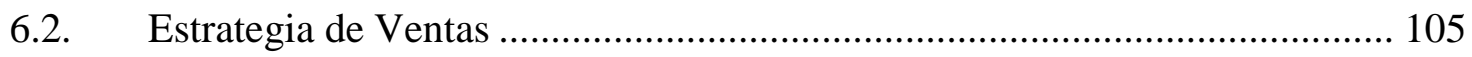

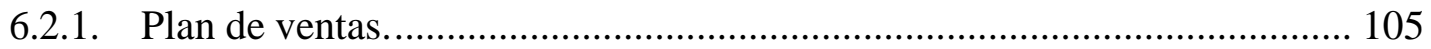

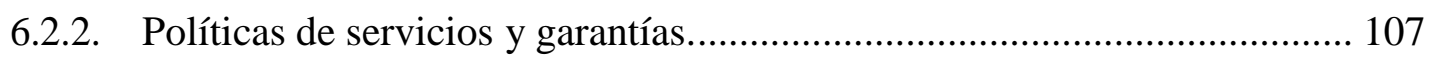

7. Capítulo VII. Pronóstico de Ventas .............................................................................109

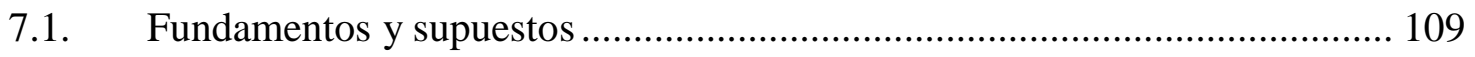

7.2. Análisis de los riesgos y aspectos críticos que impactan en el pronóstico .... 110

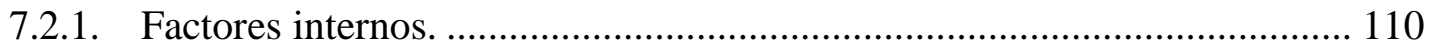

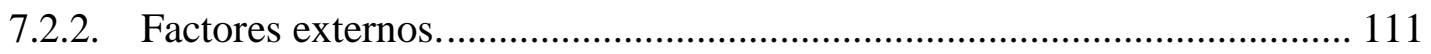

8. Capítulo VIII. Ingeniería del Proyecto …………………………………………....112

8.1. Estudio de Ingeniería .......................................................................... 112

8.1.1. Modelamiento y selección de procesos productivos................................... 112

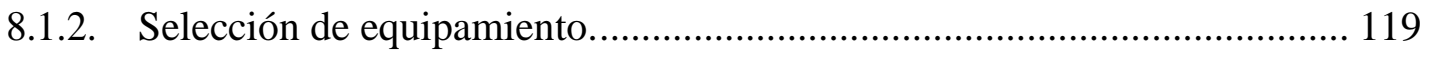

8.1.3. Lay out 124

8.1.4. Determinación de equipos y maquinaria.................................................. 124

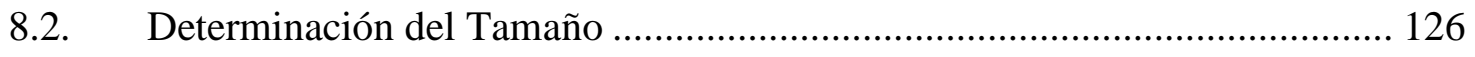

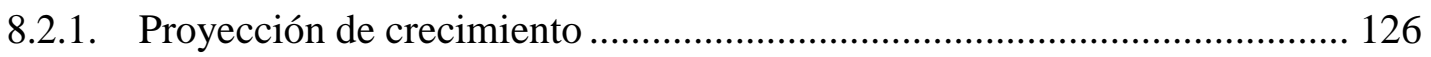

8.2.2. Recursos. 129

8.2.3. Tecnología. 129 
8.2.5. Selección del tamaño ideal..................................................................... 130

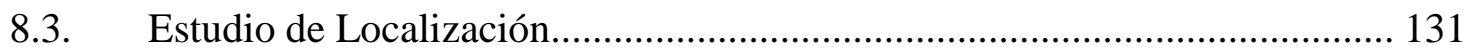

8.3.1. Definición de factores locacionales.......................................................... 131

8.3.2. Análisis de Macrolocalización ..................................................................... 131

8.3.3. Análisis de microlocalización .................................................................. 131

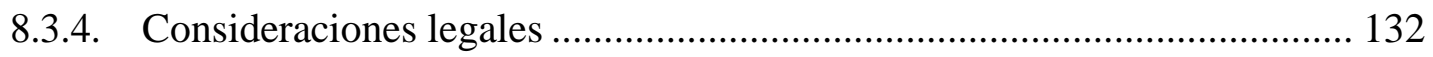

8.4. Determinación de la localización óptima ...................................................... 136

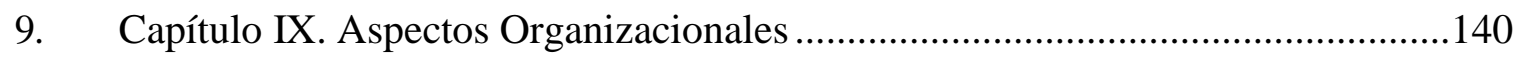

9.1. Características de la cultura organizacional deseada..................................... 140

9.1.1. Visión $\quad 140$

9.1.2. Misión $\quad 140$

9.1.3. Principios 140

9.2. Diseño De La Estructura Organizacional Del Proyecto .................................. 141

9.3. Diseño de los perfiles de puestos claves................................................... 143

9.4. Remuneraciones, Compensaciones e Incentivos ........................................... 144

9.5. Políticas de Recursos Humanos.................................................................... 146

10. Capítulo X. Estrategia Organizacional ……………..........................................150

10.1. Formulación de estrategias del negocio........................................................ 150

10.2. Determinación de los Factores Claves del Éxito ............................................ 169

10.3. Formación de la ventaja competitiva.......................................................... 170

10.3.1. Análisis de la matriz VRIO .................................................................. 172

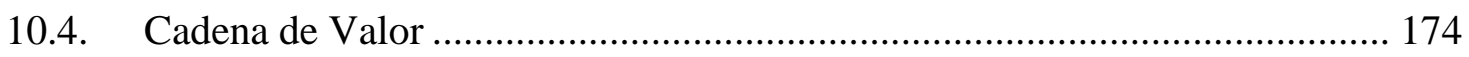

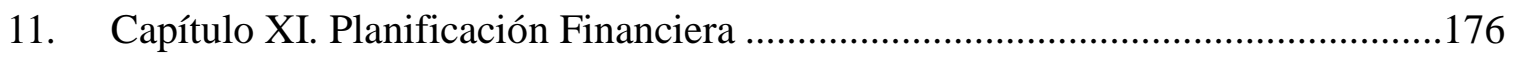




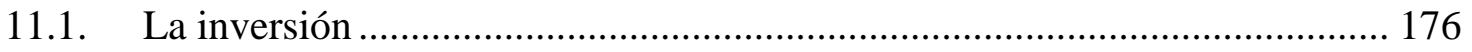

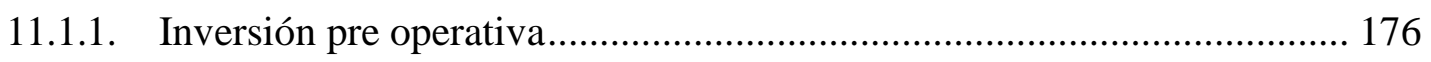

11.1.2. Inversión en capital de trabajo. ............................................................. 178

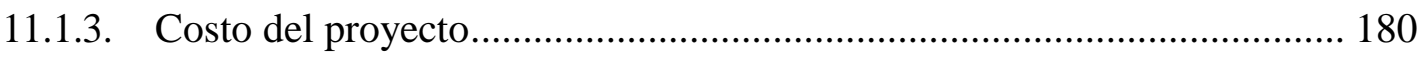

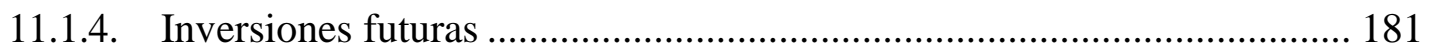

11.2. Presupuesto base (cuadro resumen) …………........................................... 182

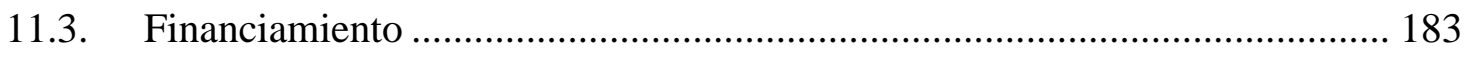

11.3.1. Endeudamiento y condiciones................................................................. 183

11.3.2. Capital y costos de oportunidad .......................................................... 186

11.3.3. Costo de capital promedio ponderado....................................................... 189

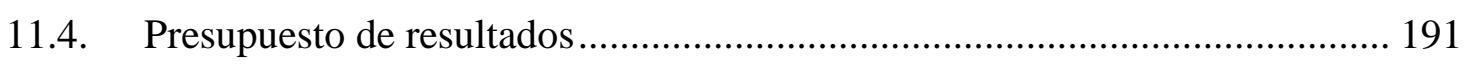

11.4.1. Estado de ganancias y pérdidas proyectados ............................................ 191

11.4.2. Balance general proyectado ………………........................................ 192

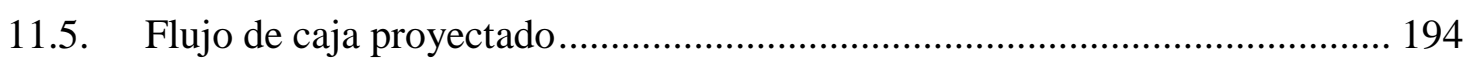

11.5.1. Flujo de caja económico........................................................................ 194

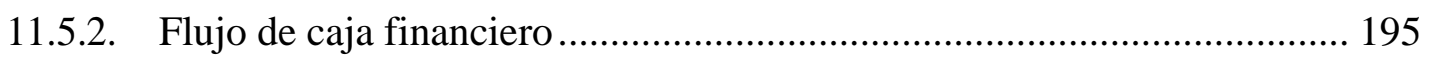

12. Capítulo XII. Evaluación Económico Financiera ………………………………....197

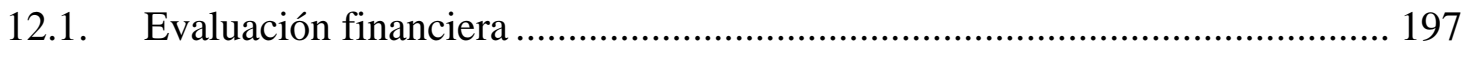

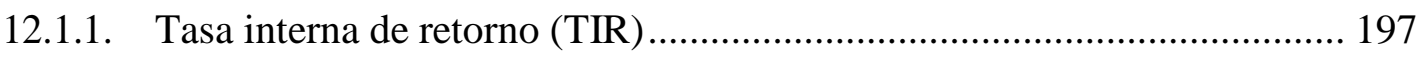

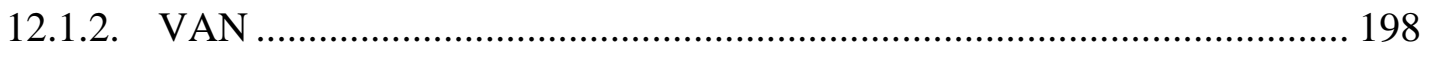

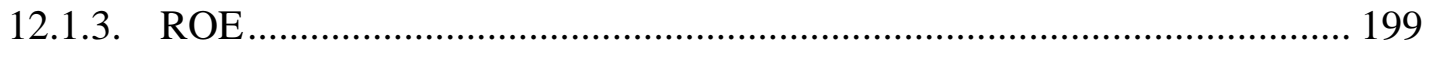

12.1.4. Análisis de punto de equilibrio............................................................... 203

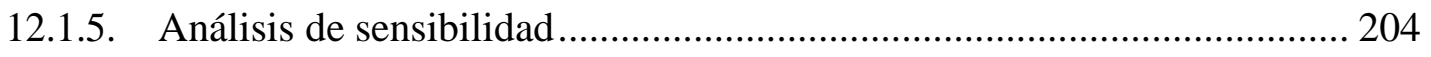

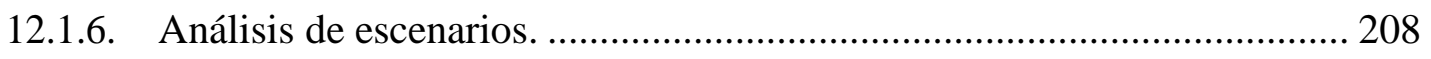




\section{Índice de Tablas}

Contenido

Pág.

Tabla 1 Sanciones a panaderías de supermercados por la municipalidad ................................. 10

Tabla 2 Producto Bruto Interno del Perú por tipo de gasto ....................................................... 29

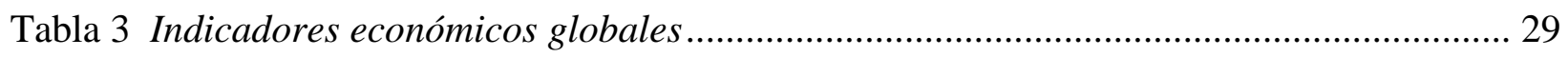

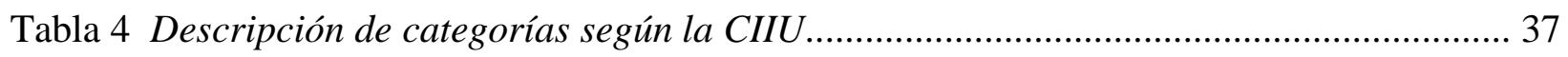

Tabla 5 Principales actividades dentro de servicios prestados a otras empresas....................... 38

Tabla 6 Tipo de empresa por número de empleados ................................................................... 39

Tabla 7 Principales servicios brindados otras empresas ........................................................... 40

Tabla 8 Lista de precios de los químicos para descarbonizar.................................................... 42

Tabla 9 Análisis de las fuerzas de Porter poder de negociación clientes..................................... 44

Tabla 10 Proveedores de insumos y maquinaria ………......................................................... 47

Tabla 11 Análisis de las fuerzas de Porter poder de negociación de proveedor equipos ............. 48

Tabla 12 Análisis de las fuerzas de Porter poder de negociación proveedor químico ................ 49

Tabla 13 Análisis de las fuerzas de Porter amenaza de sustitutos ............................................ 50

Tabla 14 Análisis de las fuerzas de Porter amenaza de nuevos competidores........................... 52

Tabla 15 Análisis de las fuerzas de Porter rivalidad entre competidores ................................... 54

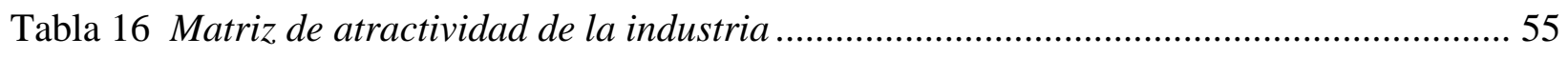

Tabla 17 Análisis interno y externo Comercial ………………................................................ 56

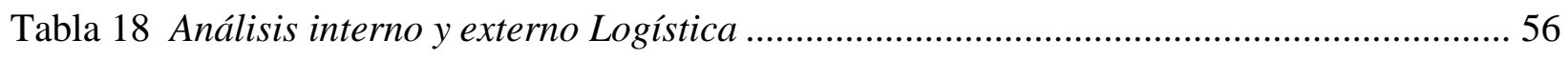

Tabla 19 Análisis externo e interno de Recursos humanos ............................................................. 57

Tabla 20 Análisis externo e interno financiero .......................................................................... 57

Tabla 21 Ficha Técnica de investigación de Mercado .............................................................. 61 
Tabla 22 Resumen de entrevistas a Profundidad parte I ....................................................... 62

Tabla 23 Resumen de entrevistas a Profundidad parte II..................................................... 63

Tabla 24 Número de tiendas a encuestar por cadena de supermercados ............................... 65

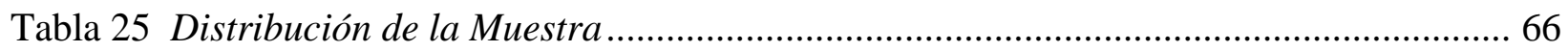

Tabla 26 Número de personal por panadería de supermercado ............................................ 68

Tabla 27 Pregunta 1. ¿Es necesario mantener las bandejas limpias para el horneado? ........... 69

Tabla 28 Pregunta 2. ¿Actualmente su área realiza lavado de bandejas? ................................ 70

Tabla 29 Pregunta 3. Indique usted ¿cuántas bandejas en total cuenta en su área?................. 71

Tabla 30 Pregunta 4. ¿Con qué frecuencia realiza el lavado de bandejas? ............................. 71

Tabla 31 Pregunta 5. ¿El lavado se realiza con personal interno o con personal externo?....... 72

Tabla 32 Pregunta 6. ¿cuántas personas de su área destina para el lavado de bandejas?........ 72

Tabla 33 Pregunta 7. ¿Les es complicado realizar el lavado de bandejas? ............................. 73

Tabla 34 Pregunta 8.¿Cuánto tiempo demora en realizar el lavado de bandejas? ................... 73

Tabla 35 Pregunta 9.¿Cuántas bandejas al día logra lavar el personal interno?..................... 74

Tabla 36 Pregunta 10. Indique el motivo que le dificulta realizar el lavado de bandejas .......... 74

Tabla 37 Pregunta 11. ¿El trabajo realizado por el personal externo es eficiente?.................. 75

Tabla 38 Pregunta 12. ¿Cuántas bandejas al día logra lavar el personal externo?.................. 76

Tabla 39 Pregunta 13. Ante el cierre indique usted cual es el principal impacto..................... 76

Tabla 40 Pregunta 1. ¿Qué tan satisfecho está con la información brindada? .......................... 77

Tabla 41 Pregunta 2. ¿Usted estaría dispuesto a contratar nuestros servicios? ...................... 77

Tabla 42 Pregunta 3. ¿Con qué frecuencia contrataría nuestro servicio? .............................. 78

Tabla 43 Pregunta 4. ¿Por qué motivo usted elegiría el servicio indicado? ............................. 79

Tabla 44 Pregunta 5. ¿Cuál es el rango de precios que pagaría por el servicio?.................... 79 
Tabla 45 Pregunta 6. ¿Qué otro utensilio quisiera tratar con este servicio?

Tabla 46 Ficha Técnica de investigación de Mercado ........................................................... 84

Tabla 47 Ficha Técnica de investigación de mercado.............................................................. 85

Tabla 48 Resumen procedimiento de Investigación mixta del Proyecto .................................... 86

Tabla 49 Número de supermercados a nivel nacional y a nivel Lima y Callao ......................... 87

Tabla 50 Proyección de supermercados en Perú.................................................................... 89

Tabla 51 Proyección de los supermercados en Lima y Callao................................................ 89

Tabla 52 Proyección de supermercados a nivel nacional por participación ............................. 90

Tabla 53 Proyección de supermercados en Lima y Callao por participación ............................ 91

Tabla 54 Proyección de supermercados en Lima y Callao que hornean panes en sus locales.. 91

Tabla 55 Proyección de supermercados en Lima y Callao que hornean en sus locales y son

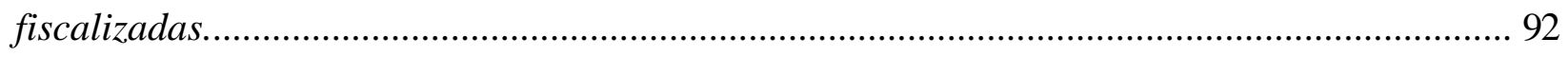

Tabla 56 Costos por lavado con personal externo e interno.................................................. 98

Tabla 57 Costos unitarios por lavado con personal externo e interno..................................... 99

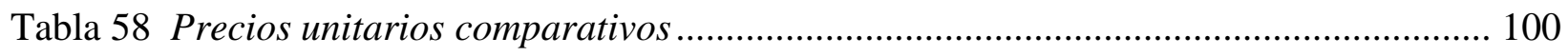

Tabla 59 Estrategias de ventas según el ciclo de vida del servicio ....................................... 105

Tabla 60 Ventas proyectadas (Nuevos Soles) …............................................................ 107

Tabla 61 Número de bandejas proyectadas del mercado objetivo ........................................ 109

Tabla 62 Ventas proyectadas (Nuevos Soles) .................................................................... 110

Tabla 63 Cantidad de supermercados del mercado objetivo por distrito de Lima y Callao..... 115

Tabla 64 Colores de precintos para la identificación por cadena de supermercados .............. 115

Tabla 65 Listado de activos de Limpia Express activos ..................................................... 119

Tabla 66 Listado de activos de Limpia Express activos ..................................................... 120 
Tabla 67 Listado de activos de Limpia Express suministros ................................................. 121

Tabla 68 Listado de activos de Limpia Express accesorios................................................... 122

Tabla 69 Listado de activos de Limpia Express mobiliario................................................. 123

Tabla 70 Programa de producción periodo 2018 al 2022 ..................................................... 127

Tabla 71 Costos de compras de productos químicos periodo 2018-2022 .............................. 128

Tabla 72 Descripción de posibles locales......................................................................... 136

Tabla 73 Matriz de micorlocalización ................................................................................... 137

Tabla 74 Distritos con mayor cantidad de supermercados ............................................... 137

Tabla 75 Escala de remuneraciones Limpia Express ....................................................... 145

Tabla 76 Matriz Amplificada de Comercial........................................................................... 153

Tabla 77 Matriz Amplificada de Comercial......................................................................... 154

Tabla 78 Matriz Amplificada de Comercial..................................................................... 155

Tabla 79 Matriz Amplificada de Comercial...................................................................... 156

Tabla 80 Matriz Amplificada de Logística.......................................................................... 157

Tabla 81 Matriz Amplificada de Logística......................................................................... 158

Tabla 82 Matriz Amplificada de Logística......................................................................... 159

Tabla 83 Matriz Amplificada de Logística........................................................................... 160

Tabla 84 Matriz Amplificada de Recursos Humanos .......................................................... 161

Tabla 85 Matriz Amplificada de Recursos Humanos .......................................................... 162

Tabla 86 Matriz Amplificada de Recursos Humanos ............................................................ 163

Tabla 87 Matriz Amplificada de Recursos Humanos .......................................................... 164

Tabla 88 Matriz Amplificada de Financiera ..................................................................... 165

Tabla 89 Matriz Amplificada de Financiera ....................................................................... 166 
Tabla 90 Matriz Amplificada de Financiera ..................................................................... 167

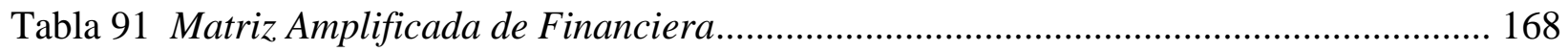

Tabla 92 Análisis de las ventajas competitivas sostenibles en el tiempo .................................. 173

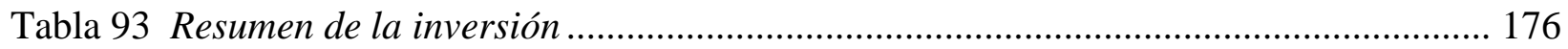

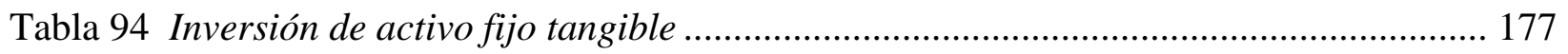

Tabla 95 Inversión de activo fijo intangible ………………....................................................... 178

Tabla 96 Capital de trabajo máximo (déficit acumulado)....................................................... 179

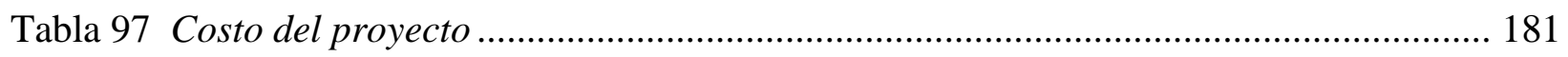

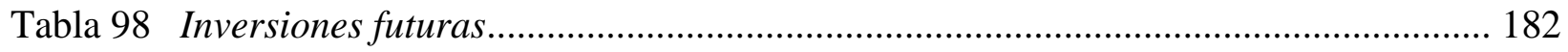

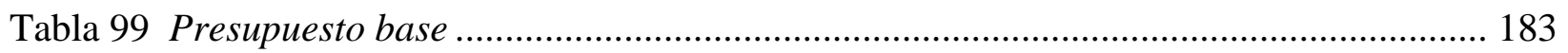

Tabla 100 Comparativo de condiciones de financiamiento....................................................... 184

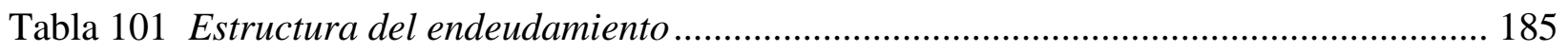

Tabla 102 Condiciones de financiamiento en "Mi Banco"...................................................... 185

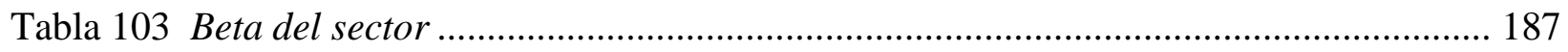

Tabla 104 Condiciones del financiamiento Ke Nominal EE. UU............................................ 187

Tabla 105 Condiciones del financiamiento Ke Real EE. UU ................................................. 188

Tabla 106 Condiciones del financiamiento Ke Real Perú ………………………................. 188

Tabla 107 Condiciones del financiamiento Ke Nominal Perú.................................................. 189

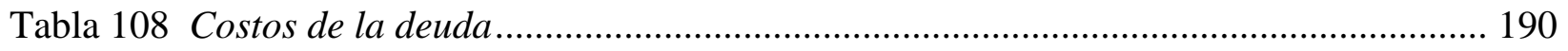

Tabla 109 Costos de Capital Promedio Ponderado (WACC) ................................................... 190

Tabla 110 Estado de Resultados Proyectados 2018-2022 (Soles)............................................ 192

Tabla 111 Balance General Proyectado 2018 - 2022 (Soles)................................................... 193

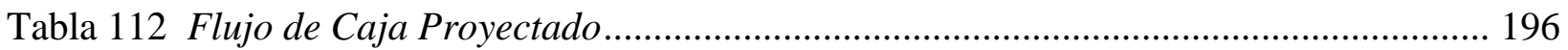


Tabla 113 Valor Actual neto (VAN) - Tasa interna de retorno (TIR).................................... 198

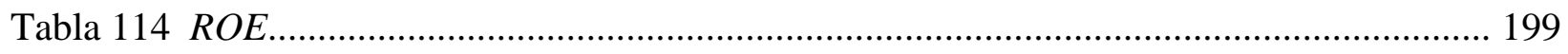

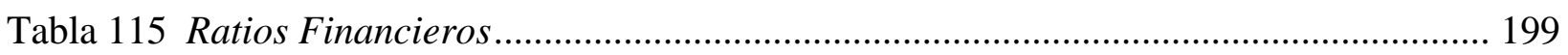

Tabla 116 Análisis de punto de equilibrio ............................................................................... 204

Tabla 117 Escenario 1, análisis de sensibilidad reducción de ventas e incremento de gastos 205

Tabla 118 Escenario 1, flujo de caja pesimista ................................................................ 206

Tabla 119 Escenario 2, análisis de sensibilidad por aumento de ventas y reducción de gastos 207

Tabla 120 Escenario 2, flujo de caja optimista ................................................................ 208

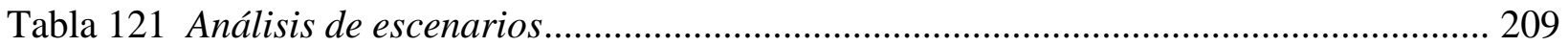




\section{Índice de Figuras}

Contenido

Pág.

Figura 1. Crecimiento de número de supermercados en el Perú. …………………………............ 5

Figura 2. Participación de supermercados en Lima y Provincia. .................................................... 5

Figura 3. Pérdida económica por cierre de un supermercado (soles)............................................. 12

Figura 4. Gastos anules comparativos por tipo de limpieza de bandejas..................................... 13

Figura 5. Mapa de posicionamiento de los servicios de limpieza de bandejas ............................. 15

Figura 6. Estructura organizacional para Limpia Express. ......................................................... 19

Figura 7. Ciclo de vida del servicio de descarbonizado de bandejas .......................................... 20

Figura 8. Bandeja semidescarbonizada para demostración de eficiencia..................................... 21

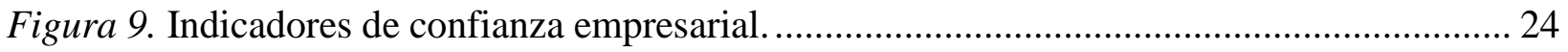

Figura 10. Proyección de la Inversión privada en el Perú................................................................ 24

Figura 11. Índice de Confianza del Consumidor - Total Nacional............................................ 25

Figura 12. Índice de Confianza del Consumidor - Lima e Interior................................................ 25

Figura 13. Índice de Confianza del Consumidor - NSE a nivel Nacional.................................. 26

Figura 14. Distribución de hogares según NSE 2017 - Lima Metropolitana ................................ 27

Figura 15. Comercio y Niveles de confianza globales ............................................................... 28

Figura 16. Inflación del Perú (var \% 12 meses)....................................................................... 30

Figura 17. Evolución del tipo de cambio mensual Perú................................................................. 31

Figura 18. PBI Sectorial Perú (var \% reales) ………………................................................... 31

Figura 19. Ciclo de vida del servicio de descarbonizado de bandejas ........................................ 36

Figura 20. Crecimiento anual del sector servicios prestados a otras empresas............................. 41

Figura 21. Análisis de las cinco fuerzas de Porter de empresas .................................................... 43 


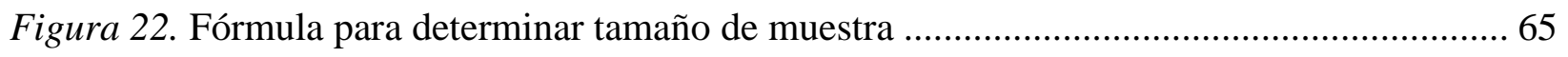

Figura 23. Regresión Lineal supermercados a nivel nacional................................................... 88

Figura 24. Regresión Lineal supermercados de Lima y Callao …………………………............ 89

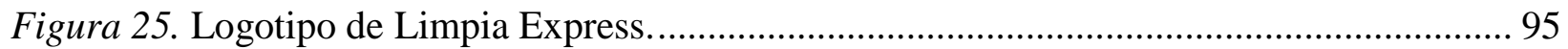

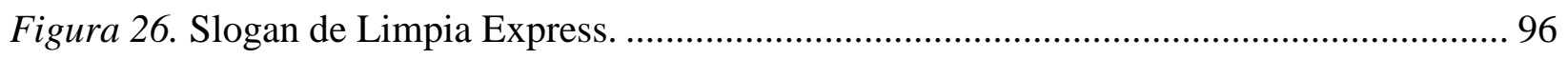

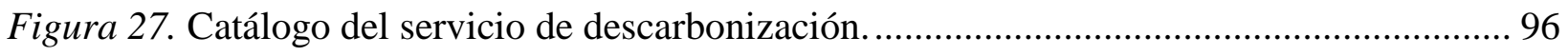

Figura 28. Modulado final de las bandejas descarbonizadas. ................................................ 97

Figura 29. Proceso de distribución de Limpia Express ............................................................... 102

Figura 30. Diagrama general del servicio de descarbonización de bandejas de panadería ......... 113

Figura 31. Las Limas y “los conos”. Fuente: Ipsos-Apoyo ………………………………......... 114

Figura 32. Diagrama de flujo del proceso de descabonización.................................................... 118

Figura 33. Distribución de las áreas de la planta de descarbonización....................................... 124

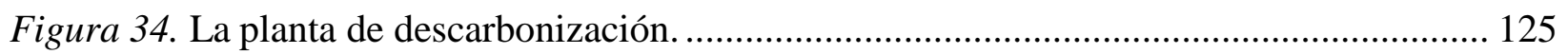

Figura 35. Mapa de distritos de Lima con mayor concentración de supermercados. .................. 138

Figura 36. Organigrama del servicio de descarbonización de bandejas de panadería ................ 142

Figura 37. Consulta de satisfacción del servicio de descarbonizado. ........................................ 152

Figura 38. Ventajas competitivas del servicio de descarbonización de bandejas de panadería. 170

Figura 39. Cadena de valor para la Limpia Express................................................................ 174 


\section{Introducción}

El presente plan de negocio busca evaluar la implementación de un servicio de descarbonización de bandejas para panaderías en supermercados de Lima y Callao, se ubicará la planta en el distrito de Lince, el objetivo principal es planificar, analizar y establecer la viabilidad del servicio.

El plan de negocio aplicado consta de 12 capítulos, los cuales se describen a continuación:

- El capítulo I, describe las generalidades del plan de negocio. Consiste en una explicación general de la oportunidad de negocio que es desarrollar el servicio de descarbonización. El cual consta de antecedentes, determinación del problema u oportunidad, factor diferenciación y de posicionamiento, objetivos, justificación, alcances y limitaciones de la investigación.

- El capítulo II, contiene información sobre la descripción de la empresa, la cual incluye la estructura de la empresa, estructura organizacional y del servicio que se ofrecerá.

- El capítulo III, detalla la estructura económica del sector, así como las tendencias mundiales y nacionales, así como, las oportunidades para este plan de negocio.

- El capítulo IV, detalla los objetivos del estudio de mercado, así como el cálculo de la muestra, técnicas e instrumentos de recolección de datos y el método de análisis de datos que se utilizó para la investigación cualitativa y cuantitativa, a fin de conocer el grado de aceptación del servicio de descarbonización

- El capítulo V, muestra la proyección de ventas en unidades y en soles del mercado. 
- El capítulo VI, define las estrategias de marketing de las 4‘p; desarrollo de producto y de distribución del servicio de descarbonización, con ayuda del análisis del marketing mix. Así como se propone estrategias y políticas de ventas.

- El capítulo VII, corresponde a los pronósticos de ventas, donde se desarrollará el fundamento y supuestos, analizando los riesgos y aspectos que impacten en el pronóstico.

- El capítulo VIII, concerniente a la factibilidad técnica de la producción y atención del servicio de descarbonización, se detalla el flujo de proceso, así como el diseño y localización de la planta.

- El capítulo IX, describen los conceptos de misión, visión y principios. Además de estructurar los cargos y responsabilidades que deben cumplir los trabajadores dentro de la planta para trabajar en equipo, de forma óptima y alcanzar las metas propuestas.

- El capítulo X, se describe la estrategia organizacional donde se determinan los factores claves del éxito, formación de ventaja competitiva y cadena de valor.

- En los capítulos XI, se da a conocer la planificación financiera en el cual se ha considerado la inversión, presupuestos, financiamiento, estado de ganancias y pérdidas, balance general y el flujo de caja.

- En los capítulos XII, se muestra la evaluación de la rentabilidad del plan de negocio, a través de la determinación del VAN, TIR y ROE, así como también se muestra el análisis de riesgo.

- Por último, se mencionan las conclusiones y recomendaciones. 